\title{
The effects of low-molecular-weight heparin administration on bleeding in elective laparoscopic cholecystectomy
}

\author{
Ulaş Aday, Ebubekir Gündeş, Hüseyin Çiyiltepe, Selçuk Gülmez, Mustafa Duman \\ Department of Gastroenterological Surgery, Kartal Koşuyolu High Speciality and Training Hospital, İstanbul, Turkey
}

\begin{abstract}
Introduction: The aim of this study was to investigate the effects of treatment dose low-molecular-weight heparin (LMWH) on bleeding in a laparoscopic cholecystectomy (LC).

Materials and Methods: The data of patients who underwent an elective LC in the clinic between January 2013 and May 2017 were retrospectively evaluated. The patients were divided into 3 groups. Group I comprised patients who were not on any anticoagulant or antiaggregant agent, Group II included patients who were taking an oral anticoagulant (OAC), and Group III was made up of patients who were on antiaggregant agents (aspirin and/or clopidogrel). The basic clinical and laboratory characteristics of the groups and the data on the surgery and complications were recorded and compared. Factors affecting major bleeding were analyzed through univariate and multivariate analysis.
\end{abstract}

Results: There were $285(80.7 \%)$ patients in Group I, while there were $30(8.4 \%)$ patients on an OAC in Group II, and $38(10.7 \%)$ patients taking antiaggregants in Group III. Major bleeding was seen in 1 patient in Group I and in Group III $(0.3 \%, 2.6 \%$ respectively), while major bleeding necessitating transfusion was seen in 5 (16.6\%) patients on an OAC in Group II $(\mathrm{p}<0.001)$. The results of univariate analysis revealed that age $\geq 65$ years, American Society of Anesthesiologists score $\geq 3$, body mass index $\geq 25 \mathrm{~kg} / \mathrm{m}^{2}$, international normalized ratio $\geq 1.2, \mathrm{PTZ} \geq 14$ seconds, administration of treatment dose LMWH (twice daily), and operation time $\geq 60$ minutes were factors that affected bleeding. The results of multivariate logistic regression analysis, however, showed that only treatment dose LMWH administration was an independent risk factor affecting major bleeding ( $p=0.021$; odds ratio (OR): 14.49, confidence interval [CI]: 0.007-0.666).

Conclusion: Bridging treatment with LMWH and interrupting OAC treatment increases the risk of major bleeding in LC. Offering patient-based bridging treatment for patients receiving long-term OAC in surgical practice and avoiding aggressive perioperative prophylaxis will reduce the risk of postoperative major bleeding.

Keywords: Bleeding; laparoscopic cholecystectomy; low-molecular-weight heparin.

\section{Introduction}

Laparoscopic cholecystectomy (LC) is one of the most common procedures performed for the treatment of symp- tomatic gallstones in surgical practice. Atrial fibrillation

(AF), mechanical heart valve (MHV), and venous throm- 
boembolism (VTE) are clinical conditions which necessitate chronic administration of oral anticoagulants (OAC). ${ }^{[1,2]}$ Moreover, aspirin and clopidogrel are antiaggregant agents used primarily for ischemic cardiac pathologies in a considerable portion of the society. ${ }^{[3,4]}$ Bleeding complications can be prevented by interruption of aspirin and clopidogrel 5 to 7 days prior to procedures in elective surgery. ${ }^{[3-6]}$ Bridging treatment utilized to prevent thromboembolism in long-term OAC received, however, increases the risk of bleeding in invasive procedures. ${ }^{[7-10]}$ OAC administration is generally stopped 5 days prior to the procedure and unfractioned heparin (UFH) or low-molecular-weight-heparin (LMWH) is used to prevent thromboembolism. LC is acknowledged to be a low-risk surgical procedure with regards to bleeding in Vitamin $\mathrm{K}$ antagonist interruption. ${ }^{[1,9]}$ Treatment dose LMWH administration for the prevention of thromboembolism increases the risk of bleeding significantly. ${ }^{[1,11,12]}$ Bridging treatment utilized for various clinical conditions and surgical procedures still proves to be a current, controversial, and dynamic issue. ${ }^{[9,13]}$

Patients using long-term OAC are a demanding group in surgical practice as per their vulnerability to bipolar complications like bleeding and thromboembolism. The aim of this study was to investigate the effects of LMWH bridging treatment following the interruption of OAC treatment on bleeding in LC.

\section{Materials and Methods}

The cases of patients who had elective LC in our clinic between January 2013 and May 2017 were retrospectively evaluated. The consent of the board of ethics was obtained for the study in line with the Declaration of Helsinki. Patients older than 18 years with complete archival data were included in the study. Open cholecystectomy, cholecystectomy performed in together with different surgical procedures, chronic liver disease, chronic renal disease, hematologic pathologies that constitute hemorrhage diathesis (such as idiopathic thrombocytopenic purpura, hemophilia A, B, von Willebrand's disease), and emergency cholecystectomy were excluded from the study. Patients who converted to open due to uncontrollable bleeding during surgery were included in the study.

Data on age, sex, body mass index (BMI), comorbid conditions, the American Society of Anesthesiologists (ASA) score, anticoagulant-antiaggregant agents used, previous history of abdominal surgery, indications of cholecystectomy, laboratory results, surgical results, presence of postoperative hemorrhaging, blood product transfusion, duration of hospitalization, morbidity and mortality were recorded.

Hemorrhage during the surgery necessitating postoperative transfusion, relaparotomy due to bleeding, decrease in hemoglobin levels by $2 \mathrm{gr} / \mathrm{dl}$ and more were acknowledged to be major bleeding. The duration of hospitalization was set as the period beginning from the day of the surgery to the discharge of the patient. Data on morbidity, mortality, and thromboembolism seen within the first 30 days were recorded as well. The patients were divided into 3 groups: Group I covered patients who were not on any anticoagulant or antiaggregant agent, Group II included patients who were on OAC, while Group III had patients who were on antiaggregant agents (aspirin and/or clopidogrel). The clinical, laboratory, and surgical results of the groups were compared. Patients with major bleeding were acknowledged to be dependent variables and univariate and multivariate analyses were conducted.

Aspirin and clopidogrel administration was stopped 5-7 days before the surgical procedure. The patients were started on antiaggregant agents on the first postoperative morning if there were no signs of bleeding. OAC was discontinued 5 days before the scheduled surgery day. Prothrombin time (PT) and international normalized ratio (INR) levels were found preoperatively and the procedure was performed on the condition that the INR level was lower than 1.5. When the INR levels dropped below treatment value enoxaparin was subcutaneously administered twice daily as LMWH at the $1 \mathrm{mg} / \mathrm{kg}$ dosage. The procedures were performed at least 12 hours after LMWH administration. LMWH administration was continued after at least 12 hours if there were no signs of postoperative bleeding and OAC was restarted on the postoperative first day. The INR levels were calculated daily in the postoperative period. LMWH administration was stopped after INR levels went up to the treatment level. In the presence of postoperative bleeding, patients were followed up with close hemodynamical monitorisation and consecutive complete blood count result controls, LMWH was discontinued and OAC treatment was not started. LMWH and OAC were administered in a controlled manner following hemorrhage control and clinical stabilization. Infective endocarditis prophylaxis was conducted upon the recommendations of the cardiology department.

Laparoscopic cholecystectomy was performed by introducing the Veress needle from the umbilical area at the 
pressure of 12-14 mm Hg pneumoperitonium using 4 standard ports. Hemostasis of the hepatic bed and port entry points were carefully conducted and drains were placed in the suphepatic area in almost all the cases if OAC use was present.

\section{Statistical Analysis}

The Statistical Package for the Social Sciences (SPSS 21 Inc., Chicago, IL, USA) software was used to conduct biostatistical analyses for the study. Data collected from the patients covered by the study were stated in mean and standard deviation values and also in percentages where necessary. The distribution of the data was checked by the Kolmogorov-Simirnov test. While ANOVA test was used in the multi-group comparisons of normally distributed data, the Kruskal-Wallis analysis was utilized in the multi-group comparisons of non-parametric data. Categorical groups were compared by the Chi-square test. Univariate logistic regression analysis of each variable was conducted in order to ascertain the variables nominated to enter into the model as the first step in the setting up process of the multivariate logistic regression model for the factors related to hemorrhage. In the event of the probability value of the Wald test statistics was lower than the error value which was set at $0.25(p<0.25)$ the related variables were included in the multivariate model. The odds ratio (OR) and 95\% confidence interval $(95 \% \mathrm{CI})$ of the results were calculated and statistical significance was set at the $\mathrm{p}<0.05$ level.

\section{Results}

Four hundred and twenty seven patients underwent cholecystectomy between January 2013 and May 2017. A total of

\section{Table 1. Clinical characteristics of the groups}

\begin{tabular}{|c|c|c|c|c|}
\hline Variables & Grup I & Grup II & Grup III & $\mathbf{p}$ \\
\hline Age (years), (Mean $\pm S D)$ & $48 \pm 13$ & $58 \pm 14$ & $59 \pm 11$ & $<0.001^{*}$ \\
\hline \multicolumn{5}{|l|}{ Sex, n (\%) } \\
\hline Male & $71(24.9)$ & $8(26.7)$ & $26(68.4)$ & \multirow[t]{2}{*}{$<0.001^{\star *}$} \\
\hline Female & $214(75.1)$ & $22(73.3)$ & $12(31.6)$ & \\
\hline \multicolumn{5}{|l|}{ Comorbidity, n (\%) } \\
\hline Hypertension & $86(30.2)$ & $16(53.3)$ & $22(57.9)$ & $<0.001^{\star *}$ \\
\hline Diabetes mellitus & $102(35.8)$ & $9(30.0)$ & $13(34.2)$ & 0.813 \\
\hline Chronic obstructive polmonary disease & $24(8.4)$ & $3(10)$ & $5(13.2)$ & 0.623 \\
\hline Coronary artery disease & $9(3.2)$ & $5(16.7)$ & $34(89.5)$ & $<0.001^{* *}$ \\
\hline Body mass index $\left(\mathrm{kg} / \mathrm{m}^{2}\right),($ Mean $\pm \mathrm{SD})$ & $29.8 \pm 4.5$ & $29.8 \pm 5.8$ & $29.8 \pm 5.4$ & 0.995 \\
\hline \multicolumn{5}{|l|}{ American Society of Anesthesiologists, $\mathrm{n}(\%)$} \\
\hline 1 & $115(40.4)$ & 0 & 0 & \multirow[t]{4}{*}{$<0.001^{* *}$} \\
\hline 2 & $141(49.5)$ & $8(26.7)$ & $14(36.8)$ & \\
\hline 3 & $29(1.2)$ & $22(73.3)$ & $23(60.5)$ & \\
\hline 4 & 0 & 0 & $1(2.6)$ & \\
\hline \multicolumn{5}{|l|}{ Indication of cholecystectomy, n (\%) } \\
\hline Biliary colic & $209(73.3)$ & $24(80)$ & $25(65.8)$ & \multirow[t]{5}{*}{0.534} \\
\hline Acut cholecystitis & $41(14.4)$ & $4(13.3)$ & $7(18.4)$ & \\
\hline Biliary pancreatitis & $12(4.2)$ & $2(6.7)$ & $4(10.5)$ & \\
\hline Polyp & $7(2.5)$ & 0 & 0 & \\
\hline Gallbladder stone and choledocolythiasis $\pm \mathrm{ERCP}$ & $16(5.6)$ & 0 & $2(5.3)$ & \\
\hline \multicolumn{5}{|l|}{ Low-moleculer-weight-heparin (dose/day), n (\%) } \\
\hline 0 & $285(100)$ & 0 & $31(81.6)$ & \multirow[t]{3}{*}{$<0.001^{* *}$} \\
\hline 1 & 0 & 0 & $5(13.2)$ & \\
\hline 2 & 0 & $30(100)$ & $2(5.3)$ & \\
\hline
\end{tabular}

*There was a significant difference between Group I and the other two groups when there was no difference between Groups II and III (Anova Post Hoc Tukey significant cerelation is examined). **Chi-square test.

ERCP. Endoscopic retrograde cholangiopancreatography; SD: Standard deviation. 
353 patients were included in the final evaluation following the exclusion of 74 cases that did not conform to the inclusion criteria of the study. Group I which did not use any anticoagulant and antiaggregant agents had 285 (80.7\%) patients, while Group II which used OAC had 30 (8.4\%) patients, and Group III which used antiaggregant agents had 38 (10.7\%) patients. Table I summarizes the clinical characteristics of the groups. The mean ages of Group I, Group II, and Group III were $48 \pm 13,58 \pm 14$ and $59 \pm 11$ respectively and while there was no difference between Group II and III, the comparison of Group I revealed a statistically significant difference $(\mathrm{p}<0.001)$. The rate of female patients in Group I and II was $75.1 \%$ and $73.3 \%$ respectively and the same rate was $31.6 \%$ for Group III and the difference between them was found to be statistically significant $(\mathrm{p}<0.001)$. Coronary artery disease (CAD) was present in almost all the patients in Group III (34/38). The number of patients with ASA score of 3 in Group I, II, and III was 29 (1.2\%), 22 (73.3\%), and $23(60.5 \%)$ respectively and the patients in Group I were prominently in the ASA 1 and 2 groups $(p<0.001)$. All the patients in Group II and 2 patients from Group III administered perioperative treatment dose LMWH. These two patients in Group III were administered LMWH not only because of coronary artery disease but also of their previous history of venous thromboembolism. While the indication of cholecystectomy was similar in each of the three groups, the most frequent reason was biliary colic (Table 1).

Table 2 summarizes the laboratory parameters, surgical time, drain use, postoperative bleeding, and dura- tion of hospitalization of the groups. The mean INR/PT values of Group I and III were 1.026 $\pm 0.14 / 12.6 \pm 0.56$ and $1.04 \pm 0.13 / 12.8 \pm 0.85$, and the results were similar. The same value for Group II, however, was 1.14 $\pm 0.15 / 14.1 \pm 1.57$ and this result was found to be higher than those of Group I and III ( $\mathrm{p}<0.001)$. The mean surgical time of Group III was $71.18 \pm 25.66$ which was longer than those of the other two groups. Drain was used in 27/30 (90\%) patients in Group II. Major bleeding was seen in one patient in Group I and Group III ( $0.3 \%$ and $2.6 \%$ respectively), while major bleeding necessitating transfusion was observed in 5 $(16.6 \%)$ patients in OAC using Group II ( $\mathrm{p}<0.001)$. Thromboembolic complications and mortality was not seen in any of the patients within the first 30 days. The mean duration of hospitalization of the groups was $1.43 \pm 0.686$, $3.5 \pm 2.86$ and $2 \pm 0.87$ respectively with the longest hospitalization in Group II ( $\mathrm{p}<0.001)$.

Table 3 displays the OAC intake indications of Group II patients on oral anticoagulant agents. Mitral valve replacement (MVR) was the reason for OAC administration in $12(40 \%)$ patients, while atrial fibrillation (AF) was the reason in $5(16.6 \%)$, MVR+AF were the reasons in 4 (13.3\%), aortic valve replacement (AVR) was the reason in 4 (13.3\%), MVR+AVR were the reasons in 2 (6.6\%), deep vein thrombosis (DVT) and pulmonary embolism (PE) were the reasons in $3(10 \%)$ patients. All the patients in Group II were administered LMWH as bridging treatment twice daily. In this group, major bleeding occurred in 5 patients $(16.6 \%)$ and minor bleeding occurred in 2 patients

Table 2. Laboratory, surgical and clinical results of the groups

\begin{tabular}{lcccc} 
Variable & Grup I & Grup II & Grup III & p \\
\hline International normalized ratio (normal $0.89-1.2)$ & $1.026 \pm 0.14$ & $1.14 \pm 0.15$ & $1.04 \pm 0.13$ & $<0.001^{*}$ \\
Prothrombin time (seconds; normal 10-14) & $12.6 \pm 0.56$ & $14.1 \pm 1.57$ & $12.8 \pm 0.85$ & $<0.001^{*}$ \\
White blood cell count $\left(\times 10^{\circ} / \mathrm{L}\right)$ & $7.2 \pm 1.71$ & $7.1 \pm 1.49$ & $7.9 \pm 2.24$ & 0.092 \\
Hemoglobin $(\mathrm{gr} / \mathrm{dL})$ & $13.32 \pm 1.41$ & $12.83 \pm 1.51$ & $13.84 \pm 1.69$ & 0.085 \\
Platalet $\left(\times 10^{\%} / \mathrm{L}\right)$ & $258 \pm 79$ & $266 \pm 71$ & $241 \pm 61$ & 0.382 \\
Serum alanine amino transferase & $26.6 \pm 23.51$ & $28.3 \pm 18.14$ & $26.9 \pm 15.34$ & 0.928 \\
Bilirubine $(\mathrm{mg} / \mathrm{dL})$ & $0.58 \pm 0.44$ & $0.71 \pm 0.32$ & $0.58 \pm 0.25$ & 0.252 \\
Creatinine $(\mathrm{mg} / \mathrm{dL})$ & $0.67 \pm 0.18$ & $0.74 \pm 0.19$ & $0.85 \pm 0.16$ & 0.108 \\
Surgery time $(\mathrm{minutes})$ & $54.8 \pm 13.33$ & $64 \pm 16.31$ & $71.18 \pm 25.66$ & $<0.001^{* *}$ \\
Drain, $\mathrm{n}(\%)$ & $67(23.5)$ & $27(90)$ & $26(68.4)$ & $<0.001^{* * *}$ \\
Major bleeding, $\mathrm{n}(\%)$ & $1 / 285(0.3)$ & $5 / 30(16.6)$ & $1 / 38(0.2)$ & $<0.001$ \\
Length of stay in hospital (day) & $1.43 \pm 0.686$ & $3.5 \pm 2.86$ & $2 \pm 0.87$ & $<0.001^{* * *}$ \\
\hline
\end{tabular}

*According to Anova Post Hoc Tukey there is no difference between groups I and III, where as there is diference between Group II and other groups. **According to Anova Post Hoc Tukey there is no difference between groups II and III, whereas there is diference between Group I and other groups. *** Chi square test. ****Accrding to Anova Post Hoc Tukey, significant difference was found between the three groups. 
Table 3. Clinical characteristics of patients with oral anticoagulants group (Grup II)

\begin{tabular}{lcccc} 
Anticoagulant reason & $\mathbf{n}$ & $\%$ & Major bleeding (n) & Minor bleeding (n) \\
\hline Mitral valve replasement & 12 & 40 & 2 & 1 \\
Atrial fibrillasion & 5 & 16.6 & 0 & 0 \\
Mitral valve replasement+atrial fibrillasion & 4 & 13.3 & 1 & 1 \\
Aortic valve replacement & 4 & 13.3 & 1 & 0 \\
Mitral valve replasement+atrial fibrillasion + & & & & 0 \\
aortic valve replacement & 2 & 6.6 & 1 & 0 \\
Deep vein thrombosis and/or pulmonary embolism & 3 & 10 & 0 & $2(6.6)$ \\
Total, $\mathrm{n}(\%)$ & 30 & 100 & $5(16.6)$ &
\end{tabular}

Table 4. Univariate analysis of the risk factors for postoperative major bleeding

\begin{tabular}{|c|c|c|c|c|c|c|}
\hline Variable & $\begin{array}{c}\text { No bleeding } \\
\quad(n=346) \\
(98.01 \%)\end{array}$ & $\begin{array}{c}\text { Major bleeding } \\
(\mathrm{n}=7) \\
(0.19 \%)\end{array}$ & $\beta$ & OR & $95 \% \mathrm{Cl}$ & $\mathbf{p}$ \\
\hline Age $\geq 65$ & $45(93.7 \%)$ & $3(6.2 \%)$ & -1.613 & 5.025 & $0.043-0.920$ & $0.039^{*}$ \\
\hline Sex (Male) & $102(97.1 \%)$ & $3(2.9 \%)$ & 0.585 & 1.794 & $0.394-8.160$ & 0.449 \\
\hline ASA $\geq 3$ & $71(94.6 \%)$ & $4(5.3 \%)$ & -1.642 & 5.15 & $0.042-0.885$ & $0.034^{*}$ \\
\hline $\mathrm{BMI} \geq 25,\left(\mathrm{~kg} / \mathrm{m}^{2}\right)$ & $309(98.7 \%)$ & $4(1.27 \%)$ & 1.835 & 6.264 & $1.349-29.079$ & $0.019^{*}$ \\
\hline Hypertension & $121(97.7 \%)$ & $3(2.4 \%)$ & -0.333 & 0.717 & $0.158-3.256$ & 0.667 \\
\hline Diabetes mellitus & $122(98.4 \%)$ & $2(1.6 \%)$ & 0.309 & 1.362 & $0.260-7.122$ & 0.715 \\
\hline Coroner artery disease & $46(95.8 \%)$ & $2(4.2 \%)$ & -0.959 & 0.383 & $0.072-2.034$ & 0.260 \\
\hline INR $\geq 1.2$ (normal $0.89-1.2$ ) & $25(89.2 \%)$ & $3(10.7 \%)$ & -2.265 & 9.615 & $0.022-0.490$ & $0.004^{*}$ \\
\hline PTZ $\geq 14$ (sec; normal 10.0-14.0) & $15(83.3 \%)$ & $3(16.6)$ & -2.806 & 16.66 & $0.012-0.294$ & $0.001^{*}$ \\
\hline $\begin{array}{l}\text { Adminstration of LMWH } \\
\text { (therapeutic dose) }\end{array}$ & $27(84.3 \%)$ & $5(15.6 \%)$ & -3.386 & 29.41 & $0.006-0.183$ & $0.001^{*}$ \\
\hline Operation time $\geq 60$ minutes & $109(95.6 \%)$ & $5(4.3 \%)$ & -1.051 & 0.350 & $0.077-1.589$ & $0.174^{*}$ \\
\hline History of abdominal surgery & $94(96.9 \%)$ & $3(3.09 \%)$ & 0.698 & 0.497 & $0.109-2.264$ & 0.366 \\
\hline
\end{tabular}

*Age $\geq 65, A S A \geq 3, B M I\left(k g / m^{2}\right) \geq 25$, INR $\geq 1.2, P T Z \geq 14$, adminstration of LMWH (therapeutic dose), and operation time $\geq 60$ minutes were statistically significant on univariate analysis.

ASA: American Society of Anesthesiologists; BMI: Body mass index; LMWH: Low-moleculer-weight-heparin; INR: International normalized ratio; PT: Prothrombin time.

(6.6\%). Minor bleeding cases occurred from the drain entry point in the right lateral to the subcutaneous area in one patient while it was in the form of a hematoma in the umbilical port area. The LMWH dosage was skipped in cases with minor hemorrhage; the patients were administered fresh-frozen plasma and Vitamin K. Five cases with major bleeding were given erythrocyte suspension transfusion at amounts varying from 2 to 6 units alongside with Vitamin $\mathrm{K}$ and fresh-frozen plasma. It was observed that all the major bleeding occurred in the hepatic bed or in the intra-abdominal area. One patient with bleeding in Group I was given 3 units of erythrocyte suspension, while the patient in Group III was given 2 units of erythrocyte suspension and platelet suspension. None of the patients with major bleeding received relaparotomy, while only one patient needed intensive care follow-up.

The results of the significance test of the variables' coefficients included in each univariate model by means of Table 4 revealed that age $\geq 65$ years, ASA score $\geq 3$, BMI $\geq 25$ $\mathrm{kg} / \mathrm{m}^{2}$, INR $\geq 1.2$, PTZ $\geq 14$, treatment dose LMWH administration, and operation time $\geq 60$ minutes had statistically significant relationships with the dependent variable. These variables were ascertained to be candidates for the multivariate model. The results of the multivariate logistic regression analysis of the factors related to major bleed- 
Table 5. Multivariate analysis of the risk factors for postoperative major bleeding

\begin{tabular}{lcccc} 
Variable & $\boldsymbol{\beta}$ & $\mathbf{p}$ & Odds ratio & $\mathbf{9 5 \%} \mathbf{C l}$ \\
\hline Age $(\geq 65)$ & -1.125 & 0.256 & 0.325 & $0.047-2.258$ \\
American Society of Anesthesiologists $\geq 3$ & 0.119 & 0.911 & 1.127 & $0.138-9.198$ \\
Body mass index $\geq 25\left(\mathrm{~kg} / \mathrm{m}^{2}\right)$ & 1.709 & 0.059 & 5.522 & $0.935-32.602$ \\
International normalized ratio $\geq 1.2$ & -0.803 & 0.587 & 0.448 & $0.025-8.139$ \\
Prothrombin time $\geq 14$ & -0.178 & 0.907 & 0.837 & $0.042-16.735$ \\
Adminstration of LMWH (therapeutic dose) & -2.676 & $0.021^{*}$ & 14.49 & $0.007-0.666$ \\
Operation time $\geq 60$ minute & -0.407 & 0.666 & 0.666 & $0.105-4.221$ \\
\hline
\end{tabular}

*Perioperative administration of therapeutic dose LMWH was the only independent risk factor for postoperative major bleeding complications by multivariate analysis. LMWH: Low-moleculer-weight-heparin.

ing after LC pointed out to treatment dose LMWH administration as an independent risk factor $(\mathrm{p}=0.021$, odds ratio (OR); 14.49, confidence interval [CI]; 0.007-0.666) (Table 5). The other variables determined to be significant by the univariate analysis, however, were not ascertained to be significant by the multivariate analysis.

\section{Discussion}

The results of this study revealed that the rate of bleeding in patients receiving bridging treatment following the interruption of OAC administration was $16.6 \%$, the use of LMWH in treatment doses appears to be the only independent risk factor that increases bleeding. Bleeding after LC, which was performed through interruption antiaggregant administration 5-7 days prior to elective surgery, was minimalized. There are studies in literature which have reported that bleeding rates were $0-25 \%$ following various surgical procedures in patients on OAC. ${ }^{[14-20]}$ The surgical management of patients on long-term OAC proves to be demanding because of complications like hemorrhage and thromboembolism. The patients are categorized into risk groups according to the reasons of OAC administration and the type of invasive procedure to be performed. LC is acknowledged to be a low-risk surgical procedure with regards to bleeding ${ }^{[7,9]}$ Although LC is accepted to be low-risk regarding hemorrhaging, it is an invasive procedure with bleeding potential. We believe that it does not deserve to be defined as a low-risk procedure with regards to bleeding because of the following reasons: i) vascular injury on the abdominal wall during the insertion of the trocar, ii) injuries in the visceral or main vascular structures during the insertion of the trocar, iii) challenging dissection because of the dense adhesions formed by cholecystic attacks and the potential to switch to open surgery, iv) the close relationship of the cholecystectomy procedure with the liver which has ample blood buildup and difficulty hemostasis, v) the fact that surgical time frequently takes longer than 45 minutes. Careful hemostasis is important in all the stages of the LC procedure performed for patients on OAC because of these factors.

Vitamin K antagonists like warfarin are used for long terms in $\mathrm{AF}, \mathrm{MHV}$, and recurring venous thromboembolic events in order to prevent stroke and systemic thromboembolism. While OAC treatment that was discontinuation in the perioperative period poses a risk for thromboembolism, shortterm parenteral bridging treatment increases the risk of bleeding. ${ }^{[1]}$ The rate of major bleeding caused by bridging treatment was reported to be between $2 \%$ and $4 \%$ in studies with heterogeneous wide case series. ${ }^{[1,2,711,21]}$ This rate, however, was reported to be higher in some other studies as well. In a prospective study performed by Ercan et al ${ }^{[15]}$ bleeding was observed in 25\% (11/44). The authors also stated that the rate of bleeding was high due to the occlusion of small veins under the pneumoperitonium, opening of small vascular structures with the dropping of pressure following surgery, the presence of additional comorbid conditions in the patients, and the prolonged effects of OAC agents and therefore recommended careful hemorrhage control of especially the hepatic bed and the port insertion points. ${ }^{[15]}$ In a different study conducted at the same center offered $31.5 \%$ as the major bleeding rate. This high rate was related to the ample number of comorbid conditions in the patients, the fact that OAC administration significantly decreased the factor II, VII, IX, and XI levels, and the increase in tissue plasminogen activator (tPA). ${ }^{[16]}$ The high rate of hemorrhaging, however, might be related to the aggressive bridging treatment to prevent thromboembolism. When the treatment records of the 
patients were analyzed within the scope of our study, it was seen that LMWH was administered as a standard on the evening before the morning that the procedure would be performed, on the evening of the procedure, and on the morning of the postoperative first day. The treatment protocol entitled aggressive thromboembolism prophylaxis as recommended by the cardiology department. It was observed that 3 dose LMWH was administered within the perioperative 36-hour period. This aggressive thromboembolism prophylaxis was thought to be the reason for the high rate of bleeding in our study because it was seen that the preoperative PT and INR values of all the patients were within normal limits. Moreover, organ dysfunctions and hematological pathologies which formed hemorrhage diatheses were not present in this study group.

Our clinical practice changed LMWH administration following the results of this study. Our novel practice was reorganized as stopping the administration of LMWH an evening before the procedure and the evening of the procedure and administering LMWH on the postoperative first day after 24 hours if there were no signs of hemorrhaging. Such a change in clinical practice was encouraged by the contributions of some current studies. In a BRIDGE study conducted by Douketis et al., ${ }^{[13]}$ the authors stated that thromboembolism was seen in $4(0.4 \%)$ out of 918 patients diagnosed with $\mathrm{AF}$ who did not receive bridging treatment and in $3(0.3 \%)$ out of 895 patients who received bridging treatment, while major bleeding was seen 2.5 times higher in the group that received bridging treatment. The results of a meta-analysis covering 12,278 patients conducted by Siegal et al. ${ }^{[1]}$ revealed that there was no statistically significant difference between patients who received and did not receive bridging treatment because of $\mathrm{AF}$ and $\mathrm{MHV}$ when they were compared regarding thromboembolism. The authors, however, observed that bridging treatment increased major bleeding by 3.6 times. It seems more rational to individualize bridging treatment for each patient by planning it according to the risk categories pertaining to bleeding and thromboembolism. It was reported that treatment dose administration of heparin should be reserved for patients with MHV and high risk of thromboembolism, again for patients with $\mathrm{AF}$ which posed a high risk for thromboembolism (those who had a stroke or trans-ischemic attack within the last 3 months or those with a CHADS2 risk score of 5-6). ${ }^{[2,9]}$ In our study, there was no complication of thromboemboli within the first 30 days, which led to a tendency to flex the prophylaxis in our clinic.
Our study had some limitations. First; the study was retrospective and did not measure postoperative hemoglobin reductions in all patients using OAC. Decreases in hemoglobin levels which were asymptomatic but more than $2 \mathrm{gr} / \mathrm{dl}$ could not be determined as patients with major bleeding were taken into careful laboratory follow-ups. The second limitation of the study pertained to the limited number of cases. Third; the effects of preoperative and postoperative administration times (in hours) of LMWH treatment on bleeding could not be assessed. Finally, no results of the change in LMWH practice could be obtained.

\section{Conclusion}

Bridging treatment with LMWH administration after stopping OAC treatment increases the risk of major bleeding in LC. Current data reveal that the feared increase in risk in thromboembolic events does not occur if bridging treatment is not offered. Individualizing bridging treatment for patients on chronic OAC in surgical practice and revision of treatment protocols by cardiologists can decrease the rates of postoperative major hemorrhaging.

\section{Disclosures}

Ethichs Committee Approval: The study was approved by the Local Ethics Committee.

Peer-review: Externally peer-reviewed.

Conflict of Interest: None declared.

\section{References}

1. Siegal D, Yudin J, Kaatz S, Douketis JD, Lim W, Spyropoulos AC. Periprocedural heparin bridging in patients receiving vitamin $\mathrm{K}$ antagonists: systematic review and meta-analysis of bleeding and thromboembolic rates. Circulation 2012;126:1630-9. [CrossRef]

2. Baron TH, Kamath PS, McBane RD. Management of antithrombotic therapy in patients undergoing invasive procedures. N Engl J Med 2013;368:2113-24. [CrossRef]

3. Devereaux PJ, Mrkobrada M, Sessler DI, Leslie K, Alonso-Coello P, Kurz A, et al; POISE-2 Investigators. Aspirin in patients undergoing noncardiac surgery. $\mathrm{N}$ Engl $\mathrm{J}$ Med 2014;370:1494-503. [CrossRef]

4. Banerjee S, Angiolillo DJ, Boden WE, Murphy JG, Khalili $H$, Hasan AA, et al. Use of Antiplatelet Therapy/DAPT for Post$\mathrm{PCl}$ Patients Undergoing Noncardiac Surgery. J Am Coll Cardiol 2017;69:1861-70. [CrossRef]

5. Levine GN, Bates ER, Bittl JA, Brindis RG, Fihn SD, Fleisher LA, et al. 2016 ACC/AHA Guideline Focused Update on Duration of Dual Antiplatelet Therapy in Patients With Coronary Artery Disease: A Report of the American College of Cardiology/ 
American Heart Association Task Force on Clinical Practice Guidelines. J Am Coll Cardiol 2016;68:1082-115. [CrossRef]

6. Joseph B, Rawashdeh B, Aziz H, Kulvatunyou N, Pandit V, Jehangir $Q$, et al. An acute care surgery dilemma: emergent laparoscopic cholecystectomy in patients on aspirin therapy. Am J Surg 2015;209:689-94. [CrossRef]

7. Spyropoulos AC, Douketis JD. How I treat anticoagulated patients undergoing an elective procedure or surgery. Blood 2012;120:2954-62. [CrossRef]

8. Makris M, Van Veen JJ, Tait CR, Mumford AD, Laffan M; British Committee for Standards in Haematology. Guideline on the management of bleeding in patients on antithrombotic agents. Br J Haematol 2013;160:35-46. [CrossRef]

9. Spyropoulos AC, Al-Badri A, Sherwood MW, Douketis JD. Periprocedural management of patients receiving a vitamin $\mathrm{K}$ antagonist or a direct oral anticoagulant requiring an elective procedure or surgery. J Thromb Haemost 2016;14:87585. [CrossRef]

10. Thachil J, Gatt A, Martlew V. Management of surgical patients receiving anticoagulation and antiplatelet agents. $\mathrm{Br} \mathrm{J}$ Surg 2008;95:1437-48. [CrossRef]

11. Jaffer AK, Brotman DJ, Bash LD, Mahmood SK, Lott B, White $\mathrm{RH}$. Variations in perioperative warfarin management: outcomes and practice patterns at nine hospitals. Am J Med 2010;123:141-50. [CrossRef]

12. Persson G, Strömberg J, Svennblad B, Sandblom G. Risk of bleeding associated with use of systemic thromboembolic prophylaxis during laparoscopic cholecystectomy. Br J Surg 2012;99:979-86. [CrossRef]

13. Douketis JD, Spyropoulos AC, Kaatz S, Becker RC, Caprini JA, Dunn AS, et al; BRIDGE Investigators. Perioperative Bridging Anticoagulation in Patients with Atrial Fibrillation. N Engl J Med 2015;373:823-33. [CrossRef]
14. Leandros E, Gomatos IP, Mami P, Kastellanos E, Albanopoulos $\mathrm{K}$, Konstadoulakis MM. Elective laparoscopic cholecystectomy for symptomatic gallstone disease in patients receiving anticoagulant therapy. J Laparoendosc Adv Surg Tech A 2005;15:357-60. [CrossRef]

15. Ercan M, Bostanci EB, Ozer I, Ulas M, Ozogul YB, Teke Z, et al. Postoperative hemorrhagic complications after elective laparoscopic cholecystectomy in patients receiving long-term anticoagulant therapy. Langenbecks Arch Surg 2010;395:247-53. [CrossRef]

16. Koc U, Bostanci EB, Karaman K, Ercan M, Dalgic T, Ulas M, et al. Basic hemostatic parameters in patients with long-term oral anticoagulation undergoing cholecystectomy. J Laparoendosc Adv Surg Tech A 2011;21:417-25. [CrossRef]

17. Mourelo R, Kaidar-Person O, Fajnwaks P, Roa PE, Pinto D, Szomstein S, et al. Hemorrhagic and thromboembolic complications after bariatric surgery in patients receiving chronic anticoagulation therapy. Obes Surg 2008;18:167-70. [CrossRef]

18. Iqbal CW, Cima RR, Pemberton JH. Bleeding and thromboembolic outcomes for patients on oral anticoagulation undergoing elective colon and rectal abdominal operations. J Gastrointest Surg 2011;15:2016-22. [CrossRef]

19. Belli S, Aytac HO, Yabanoglu H, Karagulle E, Parlakgumus A, Nursal TZ, et al. Results of surgery in general surgical patients receiving warfarin: retrospective analysis of 61 patients. Int Surg 2015;100:225-32. [CrossRef]

20. Mita K, Ito H, Murabayashi R, Sueyoshi $K$, Asakawa $H, \mathrm{Na-}$ betani $\mathrm{M}$, et al. Postoperative bleeding complications after gastric cancer surgery in patients receiving anticoagulation and/or antiplatelet agents. Ann Surg Oncol 2012;19:3745-52.

21. Douketis JD. Contra: "Bridging anticoagulation is needed during warfarin interruption when patients require elective surgery". Thromb Haemost 2012;108:210-2. [CrossRef] 